\title{
Genomic and Non-genomic Aldosterone Signaling
}

\author{
Michael S LaPointe* \\ Associate Professor of Biology, Indiana University Northwest, USA
}

Submission: February 21, 2017; Published: March 21, 2017

*Corresponding author: Michael S LaPointe, Associate Professor of Biology, Red Hawk Advising Fellow , Indiana University Northwest, 3400 Broadway, Gary, IN 46408, Indiana University Northwest, Tel: (219) 980-7106; Email: mslapoin@iun.edu

\section{Abstract}

Mineralocorticoids exhibit two modes of signaling. The classical mode found mainly in target epithelial tissue is dependent upon binding and activation of a cytosolic MR. Binding results in translocation to the nucleus where the MR homodimerizes and activates GRE regulated genes. A more rapid signaling pattern occurs in epithelial tissue and non-epithelial issues. Some of these effects are mediated by the classical MR trafficking to the plasma membrane where it can directly or indirectly interact with other signaling pathways. Mineralocorticoids also appear to activate other as of yet unknown receptors that contribute to the rapid signaling seen in some cells.

Keywords: Aldosterone; mineralocorticoid; mineralocorticoid receptor; transcription; hormone response element; HRE; receptor; steroid hormone

Abbreviations: GRE: Glucocorticoid Response Element; HRE: Hormone Response Element; MR: Mineralocorticoid Receptor

\section{Introduction}

Steroid hormones are lipophilic hormones based on the cholesterol molecule. Steroid hormones include the sex hormones - estrogen, progesterone, and testosterone; glucocorticoids mainly cortisol in human; and mineralocorticoids. The main mammalian mineralocorticoid is aldosterone. Steroid and steroid-like hormones such as vitamin D and thyroid hormone are lipophilic and exert their predominant actions by binding cytosolic receptors. Although aldosterone functional studies have dated back to the 1950 s studies examining receptor signaling had largely lacked compared to the other steroid receptors. There has been a renewed interest in aldosterone signaling with the recent discoveries that much pathology are associated with alterations in aldosterone [1-7]. This renewed interest has resulted in several excellent review articles documenting genomic and non-genomic effects of aldosterone [3,4,8-16] to name a few. The purpose of this short-review is to highlight major advances in the understanding of mineralocorticoid receptor (MR) signaling through the classical genomic pathway and the rapid non-genomic signaling of the MR.

Aldosterone has two modes of activation - a rapid mode that works in minutes and the classical, slow mode (see [17-22] for earlier topical reviews). The classical mode of activation involves binding of aldosterone to a cy-tosolic MR which translocates to the nucleus and induces gene transcription. The classical MR pathway often takes hours for effect and is inhibited by the MR antagonists, spironolactone and eplerenone, as well as the transcriptional and translational inhibitors, actinomycin D and cyclohexamide. In contrast, the rapid mode of activation is not affected by these com $\urcorner$ pounds.

\section{Classical MR signaling}

The classical MR is encoded by the NR3C2 gene located in locus 4q31.1. It codes for a 984 amino acid protein [8]. The cytoplasmic MR, like all steroid receptors, can be divided into several domains $[3,7,23,24]$. Typically it is divided into 6 major regions although some authors restrict this to three or four domains $[3,8,23,24]$. The N-terminal portion consists of 602 amino acids and is sub- divided into two domains [8]. The A and $\mathrm{B}$ domains in the $\mathrm{N}$-terminal are the most variable between the steroid receptors and bind to coregulators [3,8,23,24]. The central domain (C domain) is highly conserved region consisting of 66 amino acids [7,8] and possesses a DNA-binding domain with two zinc fingers. It is $94 \%$ homologous to the glucocorticoid receptor [3]. This domain is followed by a hinge region, $\mathrm{D}$, and then thecarboxal-terminal consisting of 251 amino acids $[7,8]$. 
The C-terminal is the ligand binding domain $[7,8]$ and also contributes to the binding of co-regulators [24]. Several studies have examined the requirements of the $\mathrm{C}$-terminal domain for ligand binding as recently reviewed [7,24]. For example, deletion mutations have shown that the last four residues are required for aldosterone binding [25]. The naturally occurring mutation (L979P) totally abolishes aldosterone binding and leads to pseudohypoaldosteronism [26].

The cytoplasmic MR is seen in high concentrations in specific tissues known to be mineralocorticoid sensitive such as the kidney and colon. MR immunostaining is present in all parts of the distal nephron, but is most prominent in the distal tubule and along the collecting ducts [27]. It has an equally high affinity for both aldosterone and glucocorticoids $[18,28]$. This is owing to the high homology of the ligand binding domains between the two receptors $[18,28]$. Glucocorticoids are present in the blood 100-1000 x greater than aldosterone [8]. Specificity of the cytosolic MR receptor for aldosterone over glucocorticoids such as cortisol and corticosterone is due to the presence of the enzyme,11beta-hydroxysteroid dehydrogenase $[17,18,28]$. This enzyme rapidly converts glucocorticoids to an inactive form.

The cytosolic MR has also been reported in other tissues at low levels and has been implicated for several pathologies [4]. These may be activated by either aldosterone or glucocorticoids [29-33]. Of note, aldosterone can also bind glucocorticoid receptors. Thus, there may be some redundancy and partial overlap between the mineralocorticoid and glucocorticoid systemsalthough clearly separate biological actions are associated with each one [34]. Thiscould explain some of the pathophysiological affects aldosterone has in alternative target tissues outside the kidney and colon [29-33]. Progesterone is also able to bind to the cytosolic MR with the same affinity as aldosterone and cortisol but acts as an antagonist or when acting alone as a partial agonist $[24,35,36]$. This is due to the rapid dissociation of progesterone from the MR complex [24].

Translocation of the activated cytoplasmic MR to the nucleus binds to specific DNA sequences to activate gene transcription. A sequence specific for MR binding has not been discovered. Instead, the activated MR binds to the hormone response element (HRE) of a gene that is also used by glucocorticoids the glucocorticoid response element (GRE) [3]. MR binding may also occur at progesterone activated transcription sites $[37,38]$. The HRE is composed of an inverted repeat separated by three nucleotides, which generally appears as the sequence AGAACAnnnTGTTCT [38]. This HRE binding sequence is similar for the GRE as well as progesterone and androgen binding, but different for estrogen and thyroid hormone [38].

The cytosolic MR when unbound to ligand is a large heterocomplex bound to heat shock proteins, chaperone molecules and other proteins such as HSP90, HSP70, p23, FKB51, FKBP52, 52, HOP/p60, Cyp40, and protein phosphatase 5 (PP5) $[3,24,39,40]$. Binding of these adjunct proteins keeps the receptor in a high affinity ligand binding state and prevents protein degradation by the proteasome $[24,25]$. HSP90 is critical for binding of ligand to the MR. FKBP51, FKBP52, and pp5, on the other hand, are not required to maintain the steroid receptors in their ligand-binding competent conformation, but are involved in the affinity of the receptors for their ligands. Association of FKBP52 has no affect on the ligand binding affinity for the MR but increases the affinity for the androgen, progesterone and glucocorticoid receptors. Association of FKB51 to the MR receptor, on the other hand reduces the ligand binding affinity [24].

Binding of ligand to the MR causes translocation to the nucleus. As previously stated, in epithelial cells the main ligand is aldosterone, while in non-epithelial cells it is cortisol. Upon binding of ligand, the cytoplasmic MR HSP90 dissociates from the receptor $[18,25]$. The MR is then transported to the nucleus [41,42] where it binds the GRE as a homodimer [43-45]. Hetrodimers between the MR and glucocorticoid receptor can also translocate to the nucleus [46]. It has been recently shown that there is a biphasic translocation. A rapid mode occurs with half time of $4-10$ minutes $[3,23,47,48]$ and a second slower translocation to the nucleus occurs with a half time of 40-60 minutes $[3,48]$. The role of HSP90 binding and translocation of the MR is confusing. While previous studies indicated that binding of ligand resulted in the dissociation of HSP90 [18,4345], newer studies indicate that binding of HSP90 is essential for translocation to the nucleus $[23,48]$.

Loss of HSP90 results in loss of interaction of proteins p23 and FKBP52 and ultimately dissociation from the dynein molecular motor [48]. This prevents the rapid phase of translocation although the slower phase is unaffected. In a recent study by Grossman et al. [23], binding of HSP90 to the activated MR remained intact for 6 minutes during the time that rapid translocation to the nucleus occurred and that inhibition of HSP90 prevented translocation [23]. In that same study, they demonstrated that binding of HSP90 to the MR homodimer increased binding to the GRE. They propose that binding of HSP90 helps stabilize the protein from degradation and assists in translocation to the nucleus. HSP90 also assists in MR binding to the GRE. Once bound to the GRE the HSP is removed which allows formation of the MR homodimer and gene transcription [23]. HSP90 binding is not required for DNA binding of the glucocorticoid receptor and thus HSP90 may act as a coregulator for differentiating different effects between the MR and glucocorticoid receptor that recognize the same HRE.

\section{Post-translational modifications of the cytosolic MR receptor}

The kidney MR isphosphorylated in the resting state which is critical for aldosterone binding [49,50]. However, removal of phosphate from serine/threonine residues is required for binding of the activated MR dimer to DNA [50]. Unconfirmed reports indicated that T735 and S737 phosphorylation may be responsible for this [41]. A gain of function mutation was described in the brown Norway rat at (Y73C) which accounts 
for differences in mineralocorticoid function between those and Fischer 344 rats. The mutation resulted in a greater MR transactivation induced by either aldosterone or progesterone [51]. The MR is phosphorylated within minutes of aldosterone stimulation on serine/threonine residues by PKCalpha [52]. Inhibition of PKC alpha prevented the late aldosterone response [52]. This demonstrates cross talk between the genomic and nongenomic actions of aldosterone signaling. Low concentrations of aldosterone (1 $\mathrm{nM}$ ) increased phosphorylation only on serine residues. Whereas higher concentrations (10 $\mathrm{nM}$ ) also induced phosphorylation on threonine residues.

Interaction of p53 with the cytosolic MR after stimulation with high doses of aldosterone resulted in CDK5 phosphorylation of the MR at S128 and S250 in the N-terminal domain. This resulted in decreased transcriptional activity without altering translocation to the nucleus [53]. This could be due to interference with binding of coactivators or due to differences in dimerization. MR dimerization in the cytosol prior to translocation of the nucleus fails to activate DNA transcription [23].

As mentioned above, the native unstimulated MR is a heterocomplex of several proteins. Association of HSP90 stabilizes the complex and reduces its degradation. It is also mono-ubiquitinated [54]. Phosphorylation of the MR by Erk 1/2 results in removal of the mono-ubiquitination an subsequent degradation of the MR. Aldosterone stimulation results in downregulation of the MR complex by targeting the complex to the proteosome [55]. Several studies have confirmed ligand induced poly-ubiquitination (reviewed in [8]) these have however resulted in contradictoryconclusions. Substitution of two potential targets for poly-ubiquitination, K367 and K715, failed to alter aldosterone stimulated proteosome degradation.

Five highly conserved sumoylation sites were predicted andcharacterized by mutations in MR. There are three in the $\mathrm{N}$ - terminal domain and one in theligand binding domain (K89, K399, (K428), K494, K953) (reviewed in [8]). PIAS1 is a SUMO ligase. Overexpression of PIAS1 resulted in reduced activity of a recorder gene using either the MMTV promotor or GRE. Mutationof these putative MR sumoylation sites had no effect on the transcription of the MMTV promoter, suggesting that PIAS1mediated sumoylation occurred on MR transcriptional co-factors. In contrast, when the GRE2 promoter was used, substitution of the lysine sumoylation sites resulted in increased transcriptional activity after PIAS1 treatment compared to the native MR. This suggests that sumoylationrepression is promotor dependent. It has also recently been shown that the MR can be acetylated at K677. This results in reduced recruitment of RNA polymerase II while not affecting MR nuclear translocation [8,56,57].

\section{Rapid non-genomic effects of aldosterone}

Aldosterone has been shown to exhibit several rapid nongenomic effects (see [3,8-11,14,16,58-60] for reviews). While once seemed obscure and controversial the phenomenon has now received wide-spread acceptance. In 2015 over 7000 Medline entries relate to this topic [61]. Some rapid effects of aldosterone are clearly linked to activation of the cytoplasmic MR $[9,10,14,16,62]$. Most effects, however, are not affected by spironolactone or eplerenone suggesting that they are mediated by another yet unknown receptor(s). These have been designated type IIb steroid receptors [61]. The rapid mode of activation may involve several different components acting immediately or within 15 minutes. These include activation of $\mathrm{Na}^{+} / \mathrm{H}^{+}$exchange, cAMP metabolism, mobilization of $\mathrm{Ca}^{2+}, \mathrm{PKC}$ activation, protein phosphorylation via other kinases such as sgk, protein translocation, and protease activation (prostatin) and mitogen-activated protein kinases, especially the extracellular signal-regulated kinases [13,16,61,63-69].

The nature of a membrane bound receptor has yet to be elucidated. There is reasonable evidence that a small portion of the classic cytoplasmic MR resides in the plasma membrane [14]. Rapid activation of ERK 1/2, p38 and c-Jun only occurs in cells transfected with the classic MR [62]. Moreover the water soluble MR receptor RU21318 inhibit rapid effects of aldosterone $[13,70]$. It has been proposed that the membrane bound estrogen receptor GPR1 (formally known as GPR30) is a target receptor for aldosterone [71]. The possibility is attractive in that $\mathrm{pM}$ concentrations of aldosterone activated ERK $1 / 2$ phosphorylation which was partially attenuated by GPER1 antagonists [71]. These initial studies in vascular smooth muscle have been confirmed in other studies (see $[14,58]$ for review)This finding while attractive is not without controversy [61]. Direct binding of aldosterone to GPER1 has not been demonstrated [61]. Moreover, aldosterone was not shown to replace estrogen from the receptor in a competitive assay [72]. So, for now, this still remains just an attractive possibility for "the" membrane bound MR.

Direct activation of signaling molecules can also not be ruled out. For example, aldosterone directly binds to the PKC alpha c domain with a binding affinity within its normal physiological range. Association of aldosterone to the subunit results in PKC alpha autophosphorylation $[73,74]$. The MR has been shown to interact with the EGRF receptor and that disruption of cholesterol rich regions of the membrane perturbed this interaction [75]. Aldosterone also causes the rapid phosphorylation of the IGF-1 receptor, IRS-1 and Akt via the action of PI3 kinase [76].

Aldosterone has been shown to cause a rapid activation in ERK $1 / 2$ phosphorylation. Furthermore, inhibition of non-genomic ERK1/2 phosphorylation was found to impair cytoplasmic-nuclear shuttling of MR and thereby transactivation of GRE. This effect depended on the N-terminal domain which was later shown to be directly phosphorylated by MR $[54,62]$. Because aldosterone/MR can rapidly activate ERK phosphorylation, this would suggest activation of genomic signaling by non-genomic MR effects. However, mutating the six predicted ERK1/2 sites in the A/B domain of the MR had no 
effect on trafficking but regulated the ubiquitination state of MR and therefore degradation [54].

\section{Conclusion}

Mineralocorticoids exhibit two modes of signaling. The classical mode found mainly in target epithelial tissue is dependent upon binding and activation of a cytosolic MR. Binding results in translocation to the nucleus where the MR homodimerizes and activates GRE transcriptionally regulated genes. A more rapid signaling pattern occurs in epithelial tissue and other tissues that are not typically depicted as target tissues for these hormones. Some of these effects appear to be mediated by the classical MR trafficking to the plasma membrane where it can directly or indirectly interact with other signaling pathways. Mineralocorticoids also appear to activate other as of yet unknown receptors that contribute to the rapid signaling seen in some cells.

\section{References}

1. Blasi ER, Rocha R, Rudolph AE, Blomme EA, Polly ML, et al. (2003) Aldosterone/salt induces renal inflammation and fibrosis in hypertensive rats. Kidney Int 63(5): 1791-800.

2. Brilla CG, Weber KT (1992) Mineralocorticoid excess, dietary sodium, and myocardial fibrosis. J Lab Clin Med 120(6): 893-901.

3. Gekle M, Bretschneider M, Meinel S, Ruhs S, Grossmann C (2014) Rapid mineralocorticoid receptor trafficking. Steroids 81: 103-108.

4. Jaisser F, Farman N (2016) Emerging Roles of the Mineralocorticoid Receptor in Pathology: Toward New Paradigms in Clinical Pharmacology. Pharmacol Rev 68(1): 49-75.

5. Qin W, Rudolph AE, Bond BR, Rocha R, Blomme EA, et al. (2003) Transgenic model of aldosterone-driven cardiac hypertrophy and heart failure. Circulation research 93(1): 69-76.

6. Sartorio CL, Fraccarollo D, Galuppo P, Leutke M, Ertl G, et al. (2007) Mineralocorticoid receptor blockade improves vasomotor dysfunction and vascular oxidative stress early after myocardial infarction. Hypertension 50(5): 919-925.

7. Viengchareun S, Le Menuet D, Martinerie L, Munier M, Pascual-Le Tallec, et al. (2007) The mineralocorticoid receptor: insights into its molecular and (patho)physiological biology. Nuclear receptor signaling 5: $\mathrm{e} 012$.

8. Faresse N (2014) Post-translational modifications of the mineralocorticoid receptor: How to dress the receptor according to the circumstances? J Steroid Biochem Mol Biol 143: 334-342.

9. Feldman RD (2014) Aldosterone and blood pressure regulation: recent milestones on the long and winding road from electrocortin to KCNJ5, GPER, and beyond. Hypertension 63(1): 19-21.

10. Funder JW (2011) GPR30, mineralocorticoid receptors, and the rapid vascular effects of aldosterone. Hypertension 57: 370-372.

11. Gomez-Sanchez E, Gomez-Sanchez CE (2014) The multifaceted mineralocorticoid receptor. Compr Physiol 4(3): 965-994.

12. Gomez-Sanchez EP (2016) Third-generation Mineralocorticoid Receptor Antagonists: Why Do We Need a Fourth? Journal of cardiovascular pharmacology 67(1): 26-38.

13. Grossmann C, Gekle M (2009) New aspects of rapid aldosterone signaling. Molecular and cellular endocrinology 308(1-2): 53-62.
14. Krug AW, Pojoga LH, Williams GH, Adler GK (2011) Cell membraneassociated mineralocorticoid receptors? New evidence. Hypertension 57(6): 1019-1025.

15. Meinel S, Gekle M, Grossmann C (2014) Mineralocorticoid receptor signaling: crosstalk with membrane receptors and other modulators. Steroids 91: 3-10.

16. Dooley R, Harvey BJ, Thomas W (2012) Non-genomic actions of aldosterone: from receptors and signals to membrane targets. Mol Cell Endocrinol 350(2): 223-234.

17. Agarwal MK, Mirshahi M (1999) General overview of mineralocorticoid hormone action. Pharmacol Ther 84(3): 273-326.

18. Hellal-Levy C, Fagart J, Souque A, Rafestin-Oblin ME (2000) Mechanistic aspects of mineralocorticoid receptor activation. Kidney Int 57(4): $1250-1255$.

19. Losel RM, Feuring M, Falkenstein E, Wehling M (2002) Nongenomic effects of aldosterone: cellular aspects and clinical implications. Steroids 67(6): 493-498.

20. Ngarmukos C, Grekin RJ (2001) Nontraditional aspects of aldosterone physiology. Am J Physiol Endocrinol Metab 281(6): E1122-E1127.

21. Rogerson FM, Brennan FE, Fuller PJ (2004) Mineralocorticoid receptor binding, structure and function. Mol Cell Endocrinol 217(1-2): 203212.

22. Rogerson FM, Fuller PJ (2000) Mineralocorticoid action. Steroids 65(2): 61-73.

23. Grossmann C, Ruhs S, Langenbruch L, Mildenberger S, Stratz N, et al. (2012) Nuclear shuttling precedes dimerization in mineralocorticoid receptor signaling. Chem Biol 19(6): 742-751.

24. Huyet J, Pinon GM, Fay MR, Rafestin-Oblin ME, Fagart J (2012) Structural determinants of ligand binding to the mineralocorticoid receptor. Mol Cell Endocrinol 350(2): 187-195.

25. Couette B, Jalaguier S, Hellal-Levy C, Lupo B, Fagart J, et al. (1998) Folding requirements of the ligand-binding domain of the human mineralocorticoid receptor. Mol Endocrinol 12(6): 855-863.

26. Sartorato P, Cluzeaud F, Fagart J, Viengchareun S, Lombes M, et al. (2004) New naturally occurring missense mutations of the human mineralocorticoid receptor disclose important residues involved in dynamic interactions with deoxyribonucleic acid, intracellular trafficking, and ligand binding. Mol Endocrinol 18(9): 2151-2165.

27. Farman N, Oblin ME, Lombes M, Delahaye F, Westphal HM, et al. (1991) Immunolocalization of gluco- and mineralocorticoid receptors in rabbit kidney. Am J Physiol 260: C226-C233.

28. Baker ME, Funder JW, Kattoula SR (2013) Evolution of hormone selectivity in glucocorticoid and mineralocorticoid receptors. J Steroid Biochem Mol Biol 137: 57-70.

29. Caprio M, Feve B, Claes A, Viengchareun S, Lombes M, et al. (2007) Pivotal role of the mineralocorticoid receptor in corticosteroidinduced adipogenesis. FASEB J 21(90): 2185-2194.

30. McCurley A, McGraw A, Pruthi D, Jaffe IZ (2013) Smooth muscle cell mineralocorticoid receptors: role in vascular function and contribution to cardiovascular disease. Pflugers Arch 465(12): 1661-1670.

31. McCurley A, Pires PW, Bender SB, Aronovitz M, Zhao MJ, et al. (2012) Direct regulation of blood pressure by smooth muscle cell mineralocorticoid receptors. Nat Med 18(9): 1429-1433.

32. Rickard AJ, Morgan J, Tesch G, Funder JW, Fuller PJ, et al. (2009) Deletion of mineralocorticoid receptors from macrophages protects against deoxycorticosterone/salt-induced cardiac fibrosis and increased blood pressure. Hypertension 54(3): 537-543. 
33. Sainte Marie Y, Toulon A, Paus R, Maubec E, Cherfa A, et al. (2007) Targeted skin overexpression of the mineralocorticoid receptor in mice causes epidermal atrophy, premature skin barrier formation, eye abnormalities, and alopecia. Am J Pathol 171(3): 846-860.

34. Farman N, Rafestin-Oblin ME (2001) Multiple aspects of mineralocorticoid selectivity. Am J Physiol Renal Physiol 280(2): F181-F192.

35. Hultman ML, Krasnoperova NV, Li S, Du S, Xia C, et al. (2005) The liganddependent interaction of mineralocorticoid receptor with coactivator and corepressor peptides suggests multiple activation mechanisms. Mol Endocrinol 19(6): 1460-1473.

36. Quinkler M, Meyer B, Bumke-Vogt C, Grossmann C, Gruber U, et al. (2002) Agonistic and antagonistic properties of progesterone metabolites at the human mineralocorticoid receptor. Eur J Endocrinol 146(6): 789-799.

37. Nelson CC, Hendy SC, Shukin RJ, Cheng H, Bruchovsky N, et al (1999) Determinants of DNA sequence specificity of the androgen, progesterone, and glucocorticoid receptors: evidence for differentia steroid receptor response elements. Mol Endocrinol 13(12): 20902107.

38. O’Hara B, Alvarez de la Rosa D, Rajendran VM (2014) Multiple mineralocorticoid response elements localized in different introns regulate intermediate conductance $\mathrm{K}+(\mathrm{Kcnn} 4)$ channel expression in the rat distal colon. PloS one 9(6): e98695.

39. Gallo LI, Ghini AA, Piwien Pilipuk G, Galigniana MD (2007) Differential recruitment of tetratricorpeptide repeat domain immunophilins to the mineralocorticoid receptor influences both heat-shock protein 90-dependent retrotransport and hormone-dependent transcriptional activity. Biochemistry 46(49): 14044-14057.

40. Nishi M, Ogawa H, Ito T, Matsuda KI, Kawata M (2001) Dynamic changes in subcellular localization of mineralocorticoid receptor in living cells: in comparison with glucocorticoid receptor using dualcolor labeling with green fluorescent protein spectral variants. Mol Endocrinol 15(7): 1077-1092.

41. Piwien-Pilipuk G, Galigniana MD (1998) Tautomycin inhibits phosphatase-dependent transformation of the rat kidney mineralocorticoid receptor. Mol Cell Endocrinol 144: 119-130.

42. Walther RF, Atlas E, Carrigan A, Rouleau Y, Edgecombe A, et al. (2005) A serine/threonine-rich motif is one of three nuclear localization signals that determine unidirectional transport of the mineralocorticoid receptor to the nucleus. J Biol Chem 280(17): 17549-17561.

43. Drouin J, Sun YL, Tremblay S, Lavender P, Schmidt TJ, et al. (1992) Homodimer formation is rate-limiting for high affinity DNA binding by glucocorticoid receptor. Mol Endocrinol 6(8): 1299-1309.

44. Tsai SY, Carlstedt-Duke J, Weigel NL, Dahlman K, Gustafsson JA, et al (1988) Molecular interactions of steroid hormone receptor with its enhancer element: evidence for receptor dimer formation. Cell 55(2): 361-369.

45. Wrange O, Eriksson P, Perlmann T (1989) The purified activated glucocorticoid receptor is a homodimer. J Biol Chem 264(9): 52535259.

46. Ou XM, Storring JM, Kushwaha N, Albert PR (2001) Heterodimerization of mineralocorticoid and glucocorticoid receptors at a novel negative response element of the 5-HT1A receptor gene. J Biol Chem 276(17): 14299-14307.

47. Bamberger CM, Wald M, Bamberger AM, Schulte HM (1997) Inhibition of mineralocorticoid and glucocorticoid receptor function by the heat shock protein 90-binding agent geldanamycin. Mol Cell Endocrinol 131(2): 233-240.
48. Galigniana MD, Erlejman AG, Monte M, Gomez-Sanchez C, Piwien-Pilipuk G (2010) The hsp90-FKBP52 complex links the mineralocorticoid receptor to motor proteins and persists bound to the receptor in early nuclear events. Mol Cell Biol 30(5): 1285-1298.

49. Alnemri ES, Maksymowych AB, Robertson NM, Litwack G (1991) Overexpression and characterization of the human mineralocorticoid receptor. J Biol Chem 266(27): 18072-18081.

50. Galigniana MD (1998) Native rat kidney mineralocorticoid receptor is a phosphoprotein whose transformation to a DNA-binding form is induced by phosphatases. Biochem J 333( Pt 3): 555-563.

51. Marissal-Arvy N, Lombes M, Petterson J, Moisan MP, Mormede P (2004) Gain of function mutation in the mineralocorticoid receptor of the Brown Norway rat. J Biol Chem 279(38): 39232-39239.

52. Le Moellic C, Ouvrard-Pascaud A, Capurro C, Cluzeaud F, Fay M, et al. (2004) Early nongenomic events in aldosterone action in renal collecting duct cells: PKCalpha activation, mineralocorticoid receptor phosphorylation, and cross-talk with the genomic response. J Am Soc Nephrol 15(5): 1145-1160.

53. Kino T, Jaffe H, Amin ND, Chakrabarti M, Zheng YL, et al. (2010) Cyclindependent kinase 5 modulates the transcriptional activity of the mineralocorticoid receptor and regulates expression of brain-derived neurotrophic factor. Mol Endocrinol 24(5): 941-952.

54. Faresse N, Vitagliano JJ, Staub O (2012) Differential ubiquitylation of the mineralocorticoid receptor is regulated by phosphorylation. FASEB J 26(10): 4373-4382.

55. Yokota K, Shibata H, Kobayashi S, Suda N, Murai A, et al. (2004) Proteasome-mediated mineralocorticoid receptor degradation attenuates transcriptional response to aldosterone. Endocr Res 30(4): 611-616.

56. Kang SH, Lee HA, Lee E, Kim M, Kim I (2016) Histone deacetylase inhibition, but not a mineralocorticoid receptor antagonist spironolactone, attenuates atypical transcription by an activating mutant MR (MRS 810L). Clin Exp Pharmacol Physiol 43(10): 9951003.

57. Lee HA, Lee DY, Cho HM, Kim SY, Iwasaki Y, et al. (2013) Histone deacetylase inhibition attenuates transcriptional activity of mineralocorticoid receptor through its acetylation and prevents development of hypertension. Circ Res 112(7): 1004-1012.

58. Feldman RD, Limbird LE (2015) Copernicus Revisited: Overturning Ptolemy's View of the GPER Universe. Trends Endocrinol Metab 26(11): 592-594.

59. Wendler A, Albrecht C, Wehling M (2012) Nongenomic actions of aldosterone and progesterone revisited. Steroids 77(10): 1002-1006.

60.Williams JS (2013) Evolving research in nongenomic actions of aldosterone. Current opinion in endocrinology, diabetes, and obesity 20(3): 198-203.

61. Wehling M (2017) Rapid actions of aldosterone revisited: Receptors in the limelight. J Steroid Biochem Mol Biol.

62. Grossmann C, Benesic A, Krug AW, Freudinger R, Mildenberger S, et al. (2005) Human mineralocorticoid receptor expression renders cells responsive for nongenotropic aldosterone actions. Mol Endocrinol 19(7): 1697-1710.

63. Harvey BJ, Ehrenfeld J (1988) Role of $\mathrm{Na}+/ \mathrm{H}+$ exchange in the control of intracellular $\mathrm{pH}$ and cell membrane conductances in frog skin epithelium. J Gen Physiol 92(6): 793-810.

64. Oberleithner H, Weigt M, Westphale HJ, Wang W (1987) Aldosterone activates $\mathrm{Na}+\mathrm{H}+$ exchange and raises cytoplasmic $\mathrm{pH}$ in target cells of the amphibian kidney. Proc Natl Acad Sci U S A 84(5): 1464-1468. 
65. Losel RM, Falkenstein E, Feuring M, Schultz A, Tillmann HC, et al. (2003) Nongenomic steroid action: controversies, questions, and answers. Physiol Rev 83(3): 965-1016.

66. Funder JW (2005) The nongenomic actions of aldosterone. Endocr Rev 26(3): 313-321.

67. Gekle M, Golenhofen N, Oberleithner H, Silbernagl S (1996) Rapid activation of $\mathrm{Na}+\mathrm{H}+$ exchange by aldosterone in renal epithelial cells requires $\mathrm{Ca} 2+$ and stimulation of a plasma membrane proton conductance. Proceedings of the National Academy of Sciences of the United States of America 93(19): 10500-10504.

68. Gekle M, Silbernagl S, Oberleithner H (1997) The mineralocorticoid aldosterone activates a proton conductance in cultured kidney cells. Am J Physiol 273: C1673-C1678.

69. Harvey BJ, Higgins M (2000) Nongenomic effects of aldosterone on Ca2+ in M-1 cortical collecting duct cell. Kidney Int 57(4): 1395-1403.

70. Michea L, Delpiano AM, Hitschfeld C, Lobos L, Lavandero S, et al. (2005) Eplerenone blocks nongenomic effects of aldosterone on the $\mathrm{Na}+\mathrm{H}+$ exchanger, intracellular $\mathrm{Ca} 2+$ levels, and vasoconstriction in mesenteric resistance vessels. Endocrinology 14(3): 973-980.
71. Gros R, Ding Q Sklar LA, Prossnitz EE, Arterburn JB, et al. (2011) GPR30 expression is required for the mineralocorticoid receptor-independent rapid vascular effects of aldosterone. Hypertension 57(3): 442-451.

72. Cheng SB, Dong J, Pang Y, LaRocca J, Hixon M, et al. (2014) Anatomical location and redistribution of $\mathrm{G}$ protein-coupled estrogen receptor-1 during the estrus cycle in mouse kidney and specific binding to estrogens but not aldosterone. Mol Cell Endocrinol 382(2): 950-959.

73. Alzamora R, Brown LR, Harvey BJ (2007) Direct binding and activation of protein kinase $\mathrm{C}$ isoforms by aldosterone and 17beta-estradiol. Mol Endocrinol 21(11): 2637-2650.

74. Alzamora R, Harvey BJ (2008) Direct binding and activation of protein kinase C isoforms by steroid hormones. Steroids 73(9-10): 885-888.

75. Grossmann C, Husse B, Mildenberger S, Schreier B, Schuman K, et al. (2010) Colocalization of mineralocorticoid and EGF receptor at the plasma membrane. Biochim Biophys Acta 1803(5): 584-590.

76. Holzman JL, Liu L, Duke BJ, Kemendy AE, Eaton DC (2007) Transactivation of the IGF-1R by aldosterone. Am J Physiol Renal Physiol 292(4): F1219-F1228.

\section{Your next submission with Juniper Publishers will reach you the below assets}

- Quality Editorial service

- Swift Peer Review

- Reprints availability

- E-prints Service

- Manuscript Podcast for convenient understanding

- Global attainment for your research

- Manuscript accessibility in different formats (Pdf, E-pub, Full Text, Audio)

- Unceasing customer service

Track the below URL for one-step submission https://juniperpublishers.com/online-submission.php 